\title{
What is the importance of omental metastasis in patients with endometrial cancer?
}

\author{
Taner Turan ${ }^{1}$, Issın Üreyen ${ }^{1}$, Alper Karalök ${ }^{1}$, Tolga Taşçı ${ }^{1}$, Hilal Ilgın ${ }^{1}$, Levent Keskin ${ }^{2}$, M. Faruk Kose ${ }^{1}$, Gökhan Tulunay ${ }^{1}$ \\ 'Department of Gynecologic Oncology, Etlik Zübeyde Hanum Women's Health Teaching and \\ Research Hospital, Ankara, Turkey \\ ${ }^{2}$ Department of Gynecology and Obstetrics, Ankara Atatürk Education and Research Hospital, Ankara, Turkey
}

\section{Abstract}

Objective: To identify surgico-pathologic factors, survival, and the factors determining survival in patients with omental metastasis from endometrial cancer.

Material and Methods: Patients with endometrial cancer operated on between 1993-2012 in our hospital and who had omental metastases were included. Patients with either uterine sarcoma or synchronous tumors were excluded.

Results: Omentectomy was performed in 811 patients with endometrial cancer, and omental metastasis was found in 48 (5.9\%) patients. Tumor type was endometrioid cancer in 26 patients. Omental metastasis was macroscopic and microscopic in $60 \%$ and $40 \%$ of the patients, respectively. Total omentectomy increased the chance of detection of the microscopic metastases. Among the patients with omental metastasis, $68.8 \%$ had positive peritoneal cytology, $66.7 \%$ had adnexal involvement, $60.5 \%$ had metastases in the lymph nodes, $47.9 \%$ had cervical involvement, and $29.2 \%$ had serosal involvement; $43.8 \%$ of these patients had intra-abdominal spread beyond the omentum, adnexa, and peritoneal cytology. Two-year disease-free survival (DFS) was $28.2 \%$, and 2-y overall survival (OS) was $40 \%$. The depth of myometrial invasion, grade, cytology, and status of pelvic lymph nodes affected 2-y DFS, while cervical invasion and cytology affected 2-y OS.

Conclusion: Omental metastasis in endometrial cancer means poor prognosis, and two-thirds of these patients are lost at the end of the second year. Although total omentectomy increases the chance of the detection of micrometastases, its effect on survival is controversial. New treatment modalities are necessary in this patient group. (J Turk Ger Gynecol Assoc 2014; 15: 164-72)

Key words: Endometrial cancer, omental metastases, survival

Received: 03 June, 2014

Accepted: 25 July, 2014

\section{Introduction}

Endometrial cancer is usually diagnosed in the early stages (1). The annual report of the International Federation of Gynecology and Obstetrics (FIGO) revealed that only $3 \%$ of newly diagnosed patients had stage IV disease (2). Nevertheless, stage IV disease is responsible for more than half of disease-specific mortality (3).

The extent of surgery in patients with this tumor is still controversial, although it has been staged surgically in accordance with the recommendation of FIGO since 1988. This controversy was about the necessity of routine lymphadenectomy in the staging procedure. Nevertheless, this uncertainty in lymphadenectomy has been pretty much removed with the ASTEC trial (4). This and similar trials showed that lymphadenectomy in addition to total abdominal hysterectomy and bilateral salpingo-oophorectomy does not improve survival in patients with early-stage endometrial cancer $(4,5)$. Additionally, pelvic and para-aortic lymphadenectomy increases surgical morbidity $(6,7)$, whereas whether sampling or systemic lymphadenectomy should be performed when lymphadenectomy is necessary, whether the para-aortic region should be involved, and, if involved, the upper level of para-aortic lymphadenectomy (inferior mesenteric artery or left renal vein) are not well defined.

Omentectomy is another controversy of the staging surgery performed in endometrial cancer. Omentectomy is not thought to add morbidity to the surgery, in contrast to lymphadenectomy (8). In addition, the information obtained from this procedure may help in the management. Omental metastasis is observed in $2.4 \%-8.3 \%$ of patients with endometrium cancer (8-15). Nevertheless, it is not clear who to perform omentectomy on and whether omentectomy should be performed for patients without intra-abdominal disease and without high risk factors for metastasis and recurrence. Furthermore, it is not clear how to perform omentectomy in patients without macroscopic metastases in terms of the extent of the procedure (total or infracolic omentectomy, or random biopsy). Additionally, the number of sections that should be taken for the pathologic evaluation of the omentectomy specimen is another enigma. In the literature, patients with omental metastasis have been presented in studies that analyzed heterogeneous groups 
of patients involving all stage IV patients. Patients without other intra-abdominal metastases and patients with microscopic omental metastases were included in these studies. The reports, except the studies mentioned above, were presented as very small case series or case reports. The patients with omental metastases were not analyzed with regard to surgico-pathologic characteristics and survival, and the factors determining survival have not been identified sufficiently in endometrial cancer.

In this study, the determination of surgico-pathologic factors, survival, and the factors determining survival in patients with omental metastases from endometrial cancer is aimed.

\section{Material and Methods}

\section{Study Population}

The records and pathologic reports of patients with endometrial cancer who were operated in our clinic between 1993 and 2012 were analyzed retrospectively. The patients with omental metastasis were included. Patients with uterine sarcoma, endometrioid carcinoma involving a sarcoma component, or synchronous tumors were excluded. The data related to demographic characteristics, intraoperative findings, debulking status, surgico-pathologic results, patients' treatments, success of their treatments, recurrence and the site of recurrence, and survival were collected from the hospital records. Ethics Committee Approval was taken from the local committee of our institution. Debulking status was obtained from the operative note written by the surgeon.

Patients were staged according to the 2009 FIGO criteria. Patients were evaluated with routine biochemistry, complete blood count, and lung X-ray before the operation. Abdominal and thoracic imaging and $\mathrm{Ca}-125$ were not performed routinely. Staging surgery is performed in our clinic for patients whose frozen section analysis reveals a tumor type other than endometrioid adenocarcinoma, grade 2 or grade 3 disease, myometrial invasion $\geq 1 / 2$, cervical invasion, and tumor size greater than $2 \mathrm{~cm}$. Furthermore, the patients with a preoperative pathologic diagnosis of high-risk cell type or grade 3 disease are staged directly. Staging surgery involves total abdominal hysterectomy, bilateral salpingo-oophorectomy, systematic pelvic and para-aortic lymphadenectomy, cytology, and omentectomy as a standard. Omentectomy was performed as total, infracolic, or omental biopsy according to the cell type, intraoperative examination, and decision of the surgeon. Cytoreductive surgery was performed in addition to staging surgery in case there was macroscopic disease intraoperatively. Maximal debulking was defined as no gross residual tumor after primary or recurrence surgery, and optimal and suboptimal debulking was used for patients with residual tumor $\leq 1 \mathrm{~cm}$ and $>1 \mathrm{~cm}$, respectively.

Adjuvant treatment following surgery and treatment for recurrent disease were defined in accordance with the World Health Organization criteria (16). According to this, clinical response was defined as follows: complete clinic response was clinical disappearance of gross tumor, partial clinical response was a $50 \%$ or more reduction in tumor size, stable disease was a
$50 \%$ or less reduction in tumor size or less than $25 \%$ increase in tumor size, and progressive disease was defined as an increase in tumor size more than $25 \%$ or appearance of a new tumor.

\section{Follow-up}

One month after adjuvant treatment, patients were evaluated with a gynecologic examination and abdominal computerized tomography in order to define the response to the treatment. The patients with complete clinical response were examined every 3 months in the first 2 years, every 6 months in the following 3 years, and then once every year. This assessment included vaginal examination, abdominal ultrasonography, complete blood count, and biochemistry. Lung X-ray was performed every year and additionally, in case there was clinical suspicion. When necessary, thoracic computerized tomography was used. Pap smear and Ca-125 were not used routinely. Patients without complete clinical response were evaluated again, and their treatment was re-planned.

For the pathologic examination of the omentum, sections from the macroscopic tumor or problematic regions were evaluated. Three to 5 sections were taken randomly from the normalappearing omentum.

Disease-free survival (DFS) was defined as the period between the time of surgery and the observation of the recurrence. Overall survival (OS) was the time between the surgery and death, and follow-up time was evaluated as the time between the surgery and the time that the patient was last examined (death or last visit). We defined recurrence distal to the pelvic inlet (true pelvis), recurrence between the pelvic inlet and diaphragm, and the rest of the recurrences as pelvic recurrence, upper abdominal recurrence, and extra-abdominal recurrence, respectively. We accepted ascites and peritonitis carcinomatosa as upper abdominal recurrence, while we accepted recurrence in the liver parenchyma, skin, and bone as extraabdominal recurrence.

\section{Statistical Analysis}

Statistical data were analyzed by the Statistical Package for Social Sciences (SPSS) 16.0 program working under the Windows XP operative system. Chi-square and Anova table tests were used to analyze the differences between mean values and percentages. Log-rank test was used for univariate analysis. Multivariate analysis could not be performed because of the limited number of patients in the study population. Kaplan-Meier method was used for the analysis of survival. Statistical significance was considered at $\mathrm{p}<0.05$.

\section{Results}

A total of 1576 patients with endometrial cancer were operated on between 1993 and 2012 in our clinic. Omentectomy was performed in 811 of these patients. Omentectomy was performed as total omentectomy in 70 patients and as infracolic omentectomy in 257 patients, and omental biopsy was carried out in 370 patients. There was no information regarding omentectomy for 113 patients. Omental metastasis was found in 48 (5.9\%) patients. 


\section{Overall Clinical and Surgico-pathologic Features}

At initial diagnosis, the mean age of 48 patients with omental metastasis was 58.6 years, ranging between 31 and 80 years. The preoperative Ca-125 levels of 23 patients could be obtained. The mean Ca-125 was $262 \mathrm{IU} / \mathrm{ml}$. The clinical and surgicopathologic characteristics of these patients are presented in Table 1 in detail.

Omentectomy was applied as total omentectomy in 27 patients, as infracolic omentectomy in 19 patients, and as omental biopsy in 2 patients. Metastasis was macroscopic in 29 (60\%) patients and microscopic in 19 (40\%) patients (Table 1). When the patients with macroscopic disease and the patients for whom the omentectomy type was not recorded were not included, the type of omentectomy (total vs infracolic and biopsy) increased the chance of detecting microscopic metastases (n: 6/53, 11.3\% vs n:13/616, 2.1\%; p<0.001, respectively).

The most common tumor type was endometrioid tumor, and it was detected in $54.2 \%$ of the patients. Tumor type was serous in $25 \%$, clear cell in $12.5 \%$, undifferentiated in $4.2 \%$, and mixedtype in $4.2 \%$ of the patients. Grade 3 tumor was observed in $62.5 \%$ of the patients (Table 1 ).

Adnexal spread was detected in $66.7 \%$, and cervical and serosal involvement was seen in $47.9 \%$ and $29.2 \%$ of the patients, respectively (Table 1 ). Three patients $(6.2 \%)$ did not have myometrial invasion. Ascites was observed in $40 \%$ of the patients, and there were tumoral cells in $68.8 \%$ of the peritoneal cytologies of the patients.

Para-aortic and bilateral pelvic lymphadenectomy was performed in 43 of 48 patients with omental metastases (Table 1). The mean number of removed lymph nodes was 15.3 and 30.5 for the para-aortic and pelvic regions, respectively. In total, 26 patients (60.5\%) had lymph node metastases. Nineteen patients (n:19/43, 44.2\%) had metastasis in the para-aortic region, and 19 patients (n: 19/43, 44.2\%) had tumor in the pelvic region. The mean metastatic lymph node number was 7 for both regions.

The type of omental metastases was not associated with tumor type. Omental metastases were microscopic in $11(42.3 \%)$ and 8 (36.4\%) patients with endometrioid and non-endometrioid-type tumors, respectively. Macroscopic tumor was detected in 20\% of the patients with grade 1 tumor and in $65 \%$ of the patients with grade 2 and 3 tumor. Nevertheless, these differences were not significant $(p=0.675, p=0.051$, respectively). Furthermore, the type of omental metastases was not associated with the depth of myometrial invasion ( $<1 / 2$ vs $\geq 1 / 2$ ), serosal involvement, lymph node metastases, LVSI, and adnexal spread ( $\mathrm{p}=0.058, \mathrm{p}=0.317, \mathrm{p}=0.415, \mathrm{p}=0.063, \mathrm{p}=0.297$, respectively).

Maximal debulking was achieved in 40 (83.3\%) patients. Surgery was optimal in $5(10.4 \%)$ and suboptimal in $3(6.2 \%)$ patients. The tumor spread to abdominal structures other than the omentum, adnexa, and peritoneal cytology in $43.8 \%$ of the patients. Preoperative extraperitoneal spread was not detected. Twentyone patients had an appendectomy, and tumoral involvement was seen in the appendix serosa in 14 patients (n:14/48, $29.7 \%$ ). Three patients had a splenectomy, and metastasis was detected in 2 patients (n:2/48, 4.2\%). The patient without metastases had a splenectomy because of surgical trauma. Diaphragmatic spread was observed in 3 patients (n:3/48, 6.2\%).
Table 1. Characteristic features

\begin{tabular}{|c|c|c|c|}
\hline \multicolumn{2}{|l|}{ Characteristic features } & $\begin{array}{c}\mathbf{n} / \\
\text { mean }\end{array}$ & $\begin{array}{c}\text { \%/median } \\
\text { (range) }\end{array}$ \\
\hline \multicolumn{2}{|l|}{ Age } & 58.6 & $60(31-80)$ \\
\hline \multicolumn{2}{|c|}{ Preoperative CA $125(\mathrm{IU} / \mathrm{mL})^{\mathrm{a}}$} & 262 & $58(8-1316)$ \\
\hline \multirow[t]{5}{*}{ Tumor type } & Endometrioid & 26 & 54.2 \\
\hline & Serous & 12 & 25 \\
\hline & Clear Cell & 6 & 12.5 \\
\hline & Mix & 2 & 4.2 \\
\hline & Undifferentiated & 2 & 4.2 \\
\hline \multirow[t]{3}{*}{ Grade } & 1 & 5 & 10.4 \\
\hline & 2 & 13 & 27.1 \\
\hline & 3 & 30 & 62.5 \\
\hline \multirow[t]{3}{*}{ Omentectomy } & Total & 27 & 56.2 \\
\hline & Infracolic & 19 & 39.6 \\
\hline & Biopsy & 2 & 4.2 \\
\hline \multirow[t]{2}{*}{ Metastasis to omentum } & Microscopic & 29 & 60 \\
\hline & Macroscopic & 19 & 40 \\
\hline \multirow[t]{2}{*}{ Ascites } & Negative & 19 & 40 \\
\hline & Positive & 29 & 40 \\
\hline \multirow[t]{3}{*}{ Peritoneal cytology } & Negative & 14 & 29.2 \\
\hline & Positive & 33 & 68.8 \\
\hline & Not reported & 1 & 2.1 \\
\hline \multirow[t]{2}{*}{ Adnexal metastasis } & Negative & 16 & 33.3 \\
\hline & Positive & 32 & 66.7 \\
\hline \multirow[t]{4}{*}{ Myometrial invasion } & No invasion & 3 & 6.2 \\
\hline & $<1 / 2$ & 10 & 20.8 \\
\hline & $\begin{array}{l}\geq 1 / 2 \text { and no } \\
\text { serosal invasion }\end{array}$ & 21 & 43.8 \\
\hline & Serosal invasion & 14 & 29.2 \\
\hline \multirow[t]{3}{*}{ Cervical invasion } & Negative & 25 & 52.1 \\
\hline & Glandular & 3 & 6.2 \\
\hline & Stromal & 20 & 41.7 \\
\hline \multirow{3}{*}{$\begin{array}{l}\text { Lymphovascular } \\
\text { space invasion }\end{array}$} & Negative & 7 & 14.6 \\
\hline & Positive & 24 & 50 \\
\hline & Not reported & 17 & 35.4 \\
\hline \multirow[t]{2}{*}{ Lymphadenectomy } & Performed & 5 & 10.4 \\
\hline & Not performed & 43 & 89.6 \\
\hline \multirow{2}{*}{$\begin{array}{l}\text { Number of lymph } \\
\text { nodes removed }\end{array}$} & Para-aortic & 15.3 & $15(1-36)$ \\
\hline & Pelvic & 30.5 & $30(2-70)$ \\
\hline \multirow{3}{*}{$\begin{array}{l}\text { Lymph node } \\
\text { metastasis }\end{array}$} & Only para-aortic & 19 & 44.2 \\
\hline & Only pelvic & 19 & 44.2 \\
\hline & Para-aortic and pelvic & 26 & 60.5 \\
\hline \multirow{2}{*}{$\begin{array}{l}\text { Number of metastatic } \\
\text { lymph nodes }\end{array}$} & Para-aortic & 7 & $5(1-28)$ \\
\hline & Pelvic & 7 & $5.5(1-25)$ \\
\hline \multirow{2}{*}{$\begin{array}{l}\text { Intra-abdominal } \\
\text { metastasis }^{\mathrm{b}}\end{array}$} & Negative & 27 & 56.2 \\
\hline & Positive & 21 & 43.8 \\
\hline \multirow[t]{3}{*}{$\begin{array}{l}\text { Result of primary } \\
\text { surgery }\end{array}$} & $\begin{array}{l}\text { Suboptimal } \\
\text { debulking }\end{array}$ & 3 & 6.2 \\
\hline & Optimal debulking & 5 & 10.4 \\
\hline & Maximal debulking & 40 & 83.3 \\
\hline
\end{tabular}


Two patients had diaphragmatic stripping, and argon beam laser was performed in 1 patient for tumoral debulking. Sigmoid colon resection was done for maximal debulking in 2 patients (n:2/48, 4.2\%).

Forty-three patients took adjuvant therapy. Two patients did not take adjuvant therapy, since they were lost to follow-up. Palliative treatment was given to 3 patients. Adjuvant therapy was platinum-based chemotherapy for 32 patients. Seven patients took radiotherapy, and 4 patients took sandwich therapy (3 cycles of paclitaxel+carboplatin, followed by interval radiotherapy, followed by 3 cycles of paclitaxel+carboplatin). Four patients taking adjuvant therapy were lost to follow-up during treatment. Clinical complete response was achieved in 30 (n:30/39, 77\%) patients, while progression was observed in 7 patients (n:7/39, 18\%). During treatment, 2 patients died due to a pulmonary embolism. These deaths were not considered perioperative deaths, since they died after more than 1 month following surgery.

\section{Survival Analysis}

While 2 patients refused to take chemotherapy, 4 patients did not complete therapy, 1 patient was lost to follow-up after taking the treatment, and 2 patients died of pulmonary embolism; 9 patients were not included in the survival analysis. DFS analysis was performed with 39 patients. OS analysis was performed with 35 patients, since 1 patient refused to take the treatment after recurrence and 3 patients were lost to follow-up during treatment. The median follow-up time was 15 months, ranging between 1 and 130 months. During follow-up, recurrence was observed in 31 patients (n: $31 / 39,79.5 \%$ ). The mean time to recurrence was 11 months in these patients. The Ca-125 levels of 18 patients with recurrence were known. The mean Ca-125 level of these patients was $200 \mathrm{IU} / \mathrm{ml}$ (Table 2).

One of the 31 patients with recurrence refused treatment. Among the 30 patients who took therapy, 14 patients took chemotherapy, 4 patients took chemotherapy following surgery, and 12 patients took palliative treatment. The data on response to treatment in 17 of the 18 patients who took curative therapy were available. Among these 17 patients, progression was observed in 15 patients ( $\mathrm{n}: 15 / 17,88.2 \%)$, since clinical complete response was achieved in 2 patients (n:2/17, 11.8\%). These 2 patients were the ones for whom maximal debulking was achieved during surgery that was done for recurrence. One of these patients died of disease 10 months after achieving a clinical complete response. The last status of the second patient was not known, since she was lost to follow-up.

Recurrence was outside of the pelvic region in 21 patients. There was extra-abdominal spread in 18 patients. Among them, 10 patients and 13 patients had recurrence in the lung and liver, respectively; 14 patients had recurrence in the upper abdominal region. Recurrence was only extra-abdominal in 8 patients, only in the upper abdomen in 7 patients, and only in the pelvic region in 5 patients, since 1 patient had recurrence in all three regions. Detailed data related to recurrence are presented in Table 2.

Type of adjuvant therapy was not associated with the region of recurrence. Excluding patients who took sandwich therapy and palliative treatment, $20 \%$ of the patients who took radiotherapy had recurrence in the pelvis, since this ratio was $33 \%$ for
Table 2. Characteristic features in recurrence

\begin{tabular}{|c|c|c|c|}
\hline \multicolumn{2}{|c|}{ Characteristic Features } & $\begin{array}{c}\mathbf{n} / \\
\text { mean }\end{array}$ & $\begin{array}{c}\text { \%/median } \\
\text { (range) }\end{array}$ \\
\hline \multicolumn{2}{|c|}{ CA $125(\mathrm{IU} / \mathrm{mL})^{1}$} & 200 & $155(3-525)$ \\
\hline \multicolumn{2}{|c|}{ Follow-up (month) } & 21 & $15(1-130)$ \\
\hline \multirow[t]{2}{*}{ Recurrence } & Negative & 8 & 20.5 \\
\hline & Positive & 31 & 79.5 \\
\hline \multicolumn{2}{|c|}{$\begin{array}{l}\text { Disease free survival time in patient with } \\
\text { recurrence (month) }\end{array}$} & 11 & $9(2-50)$ \\
\hline \multirow[t]{6}{*}{ Recurrence site } & Only pelvic & 5 & 16.1 \\
\hline & Only upper abdominal & 7 & 22.6 \\
\hline & Only extra-abdominal & 8 & 25.8 \\
\hline & $\begin{array}{l}\text { Pelvic +extra- } \\
\text { abdominal }\end{array}$ & 4 & 12.9 \\
\hline & $\begin{array}{l}\text { Upper abdominal+ } \\
\text { extra-abdominal }\end{array}$ & 6 & 19.4 \\
\hline & $\begin{array}{l}\text { Pelvic+upper } \\
\text { abdominal+extra- } \\
\text { abdominal }\end{array}$ & 1 & 3.2 \\
\hline \multirow[t]{2}{*}{ Exitus } & Negative & 8 & 23 \\
\hline & Positive & 27 & 77 \\
\hline \multicolumn{2}{|c|}{$\begin{array}{l}\text { Overall survival time in patient who dead } \\
\text { of disease (month) }\end{array}$} & 18 & $14(2-55)$ \\
\hline
\end{tabular}

patients in the chemotherapy group. On the other hand, there was extra-abdominal metastasis in $48 \%$ and $60 \%$ of the patients in the chemotherapy and radiotherapy groups, respectively. Nevertheless, these differences were insignificant $(p=0.555$, $\mathrm{p}=0.626$, respectively).

During the follow-up period, 27 patients (n: 27/35, 77\%) died of disease. Mean time to death was 18 months in these patients. At the end of the first year, $56.4 \%$ of the patients had recurrence, and at the end of the second year, this ratio became $71.8 \%$. Additionally, $29 \%$ and $60 \%$ of patients died of disease at the end of the first and second year, respectively. Peritoneal cytology was a prognostic factor for both 2-y DFS and 2-y OS (Figure 1, 2). Additionally, myometrial invasion and grade and status of pelvic lymph nodes were determining factors for 2-y DFS, and 2-y OS was associated with cervical invasion (Table 3). Survival was not affected by the type of omental metastases and existence of other intra-abdominal metastases. Aggressive surgery was not associated with survival statistically. Nevertheless, patients with suboptimal debulking died within 2 years. Patients with maximal debulking had a 20\% improvement in 2-y DFS compared to other patients. A decrease in 2-y DFS and 2-y OS was observed in the presence of risk factors. However, this decrease was not significant statistically, since the study population was small and these factors were not distributed proportionately (Table 3).

\section{Discussion}

Endometrial cancer metastasizes by direct spread into the myometrium, extending to the cervix, hematogenous dissemination, 


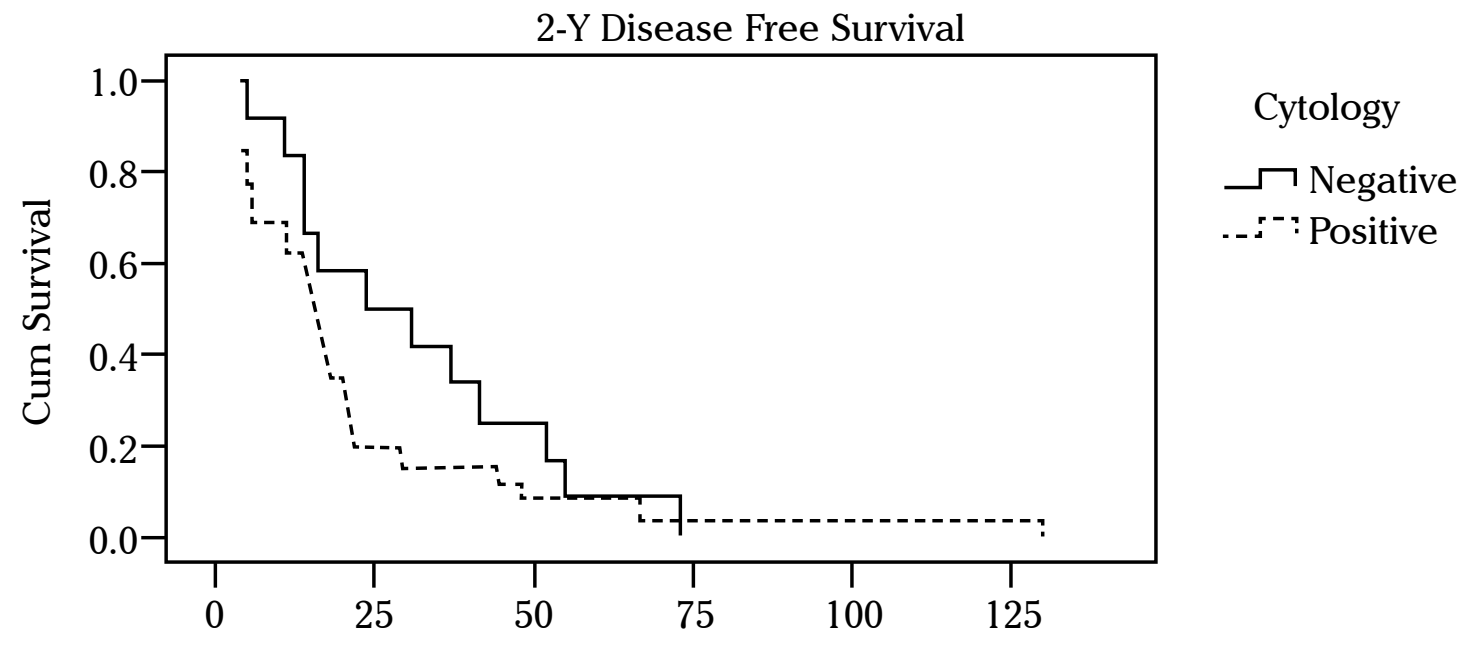

Month

Figure 1. Cytology and 2-y disease-free survival

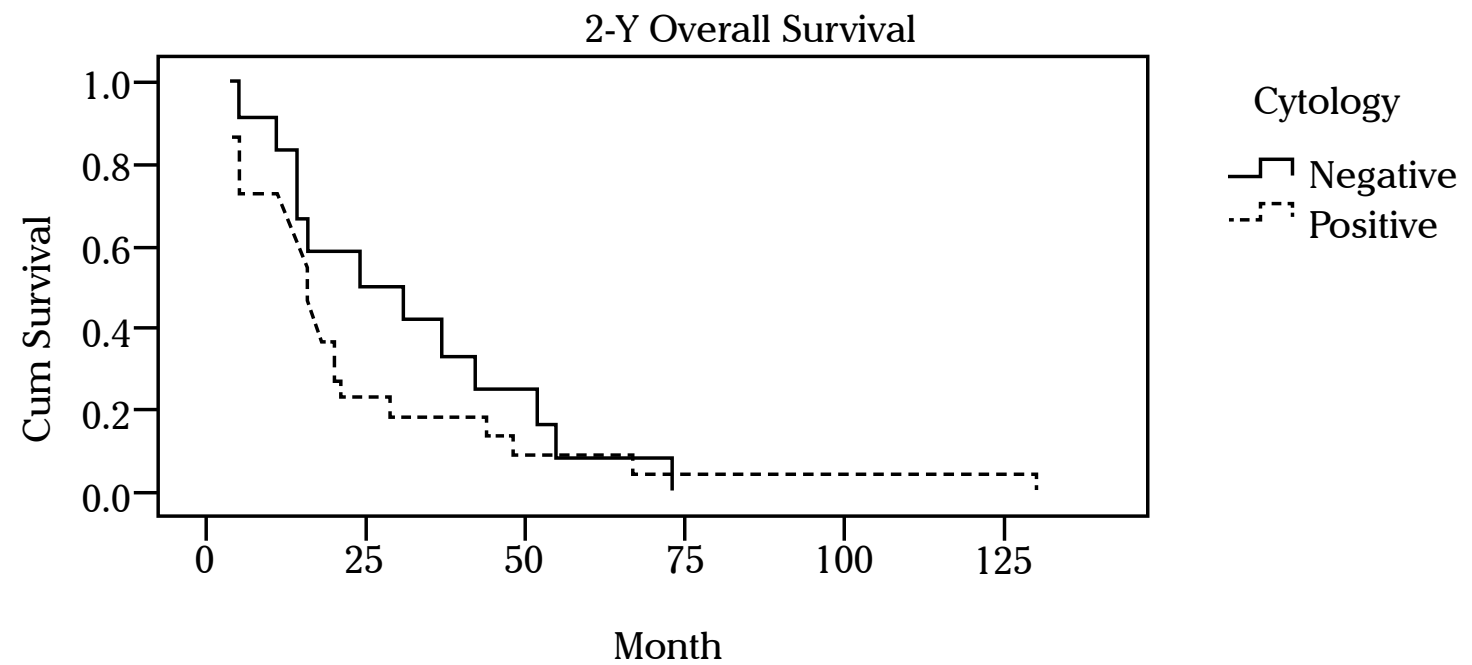

\section{Figure 2. Cytology and 2-y overall survival}

lymphatic embolization, and peritoneal seeding (17). Omental spread was thought to occur as a result of peritoneal seeding and regional lymphatics (11). On the other hand, the omentum is most probably a different region for metastases of endometrial tumor cells compared to other regions in the body. Klopp et al. (18) showed that omental adipose tissue, different from other tis- sues, stimulated the development of endometrial tumor cells and neovascularization. Omental adipose tissue was thought to promote tumor vascularization and survival and proliferation of tumor cells in comparison to subcutaneous adipose tissue.

In this study, the ratio of metastases to the omentum in the group of patients who had an omentectomy was $5.9 \%$. It was $9.1 \%$ in 
Table 3. The factors determining 2-y disease-free survival and 2-y overall survival in patients with omental metastases. Univariate analysis

\begin{tabular}{|c|c|c|c|c|c|c|c|}
\hline \multirow{2}{*}{\multicolumn{2}{|c|}{ Parameter }} & \multicolumn{3}{|c|}{ 2-year disease-free survival } & \multicolumn{3}{|c|}{ 2-year overall survival } \\
\hline & & \multirow{2}{*}{$\begin{array}{c}\mathbf{n} / \text { total n } \\
5 / 20 \\
\end{array}$} & \multirow{2}{*}{\begin{tabular}{|l|}
$\%$ \\
25 \\
\end{tabular}} & \multirow{3}{*}{$\begin{array}{c}\mathbf{p} \\
0.648\end{array}$} & \multirow{2}{*}{$\begin{array}{c}\text { n/total } \mathbf{~} \\
7 / 17 \\
\end{array}$} & \multirow{2}{*}{$\begin{array}{c}\% \\
41.2 \\
\end{array}$} & \multirow{3}{*}{$\begin{array}{c}\mathbf{p} \\
0.554\end{array}$} \\
\hline Age & $\leq 60$ & & & & & & \\
\hline & $>60$ & $6 / 19$ & 31.6 & & $5 / 16$ & 31.2 & \\
\hline \multirow[t]{2}{*}{ Tumor type } & Endometrioid & $7 / 19$ & 36.8 & \multirow{2}{*}{0.243} & $5 / 15$ & 33.3 & \multirow{2}{*}{0.741} \\
\hline & Non-endometrioid & $4 / 20$ & 20 & & $7 / 18$ & 38.9 & \\
\hline \multirow[t]{2}{*}{ Grade } & 1 and 2 & $6 / 12$ & 50 & \multirow{2}{*}{0.044} & $5 / 11$ & 45.5 & \multirow{2}{*}{0.443} \\
\hline & 3 & $5 / 27$ & 18.5 & & $7 / 22$ & 31.8 & \\
\hline \multirow[t]{2}{*}{ Depth of myometrial invasion } & $<1 / 2$ & $6 / 12$ & 50 & \multirow{2}{*}{0.044} & $5 / 10$ & 50 & \multirow{2}{*}{0.283} \\
\hline & $\geq 1 / 2$ & $5 / 27$ & 18.5 & & $7 / 23$ & 30.4 & \\
\hline \multirow[t]{2}{*}{ Uterine serosal invasion } & Negative & $10 / 27$ & 37 & \multirow{2}{*}{0.066} & $9 / 22$ & 40.9 & \multirow{2}{*}{0.443} \\
\hline & Positive & $1 / 12$ & 8.3 & & $3 / 11$ & 27.3 & \\
\hline \multirow[t]{2}{*}{ Lymphovascular space invasion } & Negative & $4 / 7$ & 57.1 & \multirow{2}{*}{0.093} & $2 / 5$ & 40 & \multirow{2}{*}{1} \\
\hline & Positive & $4 / 18$ & 22.2 & & $6 / 15$ & 40 & \\
\hline Cervical invasion & Negative & $7 / 20$ & 35 & 0.333 & $9 / 17$ & 52.9 & 0.041 \\
\hline & Positive & $4 / 19$ & 21.1 & & $3 / 16$ & 18.8 & \\
\hline Preoperative ascites & Negative & $7 / 22$ & 31.8 & 0.568 & $7 / 19$ & 36.8 & 0.947 \\
\hline & Positive & $4 / 17$ & 23.5 & 0.508 & $5 / 14$ & 35.7 & 0.947 \\
\hline Peritoneal cytology & Negative & $7 / 12$ & 58.3 & 0007 & $7 / 11$ & 63.6 & 0027 \\
\hline & Positive & $4 / 26$ & 15.4 & 0.008 & $5 / 21$ & 23.8 & $0.02 r$ \\
\hline Adnexal metastasis & Negative & $4 / 10$ & 40 & 0336 & $3 / 7$ & 42.9 & 0687 \\
\hline & Positive & $7 / 29$ & 24.1 & 0.000 & $9 / 26$ & 34.6 & 0.008 \\
\hline Other intra-abdominal metastasis ${ }^{a}$ & Negative & $8 / 22$ & 36.4 & 108 & $7 / 21$ & 33.3 & 0632 \\
\hline & Positive & $3 / 17$ & 17.6 & 0.190 & $5 / 12$ & 41.7 & 0.052 \\
\hline Type of omentectomy & Infracolic + biopsy & $5 / 17$ & 29.4 & 0883 & $5 / 16$ & 31.2 & 0554 \\
\hline & Total & $6 / 22$ & 27.3 & 0.003 & $7 / 17$ & 41.2 & 0.034 \\
\hline Omental metastasis & Microscopic & $5 / 15$ & 33.3 & 0574 & $5 / 14$ & 35.7 & 0947 \\
\hline & Macroscopic & $6 / 24$ & 25 & 0.514 & $7 / 19$ & 36.8 & 0.946 \\
\hline MicOM vs MacIM & MicOM & $4 / 10$ & 40 & 0336 & $4 / 10$ & 40 & 0775 \\
\hline & MacIM & $7 / 29$ & 24.1 & 0.050 & $8 / 23$ & 34.8 & 0.175 \\
\hline Lymphadenectomy & No & $0 / 3$ & 0 & 0258 & $0 / 2$ & 0 & 0270 \\
\hline & Yes & $11 / 36$ & 30.6 & 0.250 & $12 / 31$ & 38.7 & 0.210 \\
\hline Removed lymph nodes number & $\leq 45$ & $4 / 15$ & 26.7 & 0866 & $6 / 14$ & 42.9 & 0.506 \\
\hline & $>45$ & $7 / 24$ & 29.2 & & $6 / 19$ & 31.6 & \\
\hline Pelvic lymph node metastasis & Negative & $9 / 20$ & 45 & 0.035 & $7 / 16$ & 43.8 & 0.552 \\
\hline & Positive & $2 / 16$ & 12.5 & 0.035 & $5 / 15$ & 33.3 & 0.532 \\
\hline Para-aortic lymph node metastasis & Negative & $8 / 20$ & 40 & 0169 & $7 / 15$ & 46.7 & 0.379 \\
\hline & Positive & $3 / 16$ & 18.8 & & $5 / 16$ & 31.2 & 0.315 \\
\hline Primary cytoreduction & Optimal+Suboptimal & $1 / 8$ & 12.5 & 0.268 & $2 / 6$ & 33.3 & 0.554 \\
\hline & Maximal & $10 / 31$ & 32.3 & 0.208 & $10 / 17$ & 37 & \\
\hline Adjuvant therapy & Chemotherapy & $10 / 28$ & 35.7 & 0492 & $11 / 22$ & 50 & 0223 \\
\hline & Radiotherapy & $1 / 5$ & 20 & 0.492 & $1 / 5$ & 20 & 0.220 \\
\hline
\end{tabular}


our previous study evaluating mixed-type endometrial carcinoma (19). Similarly, the ratio of omental metastasis in endometrial cancer was reported between $2.4 \%$ and $8.3 \%$ (8-15). Nevertheless, in these studies, omentectomy was performed as infracolic omentectomy or omental biopsy. Furthermore, $11 \%-71.4 \%$ of the reported omental metastases were micrometastases $(8-15,20)$. It is not possible to say whether there were microscopic metastases or not in the remaining omentum after subtotal omentectomy. Therefore, in fact, the reported ratios related to omental metastases were minimum figures, and most probably, the ratio of omental metastasis was much higher than the reported numbers. Hence, the factors determining omental metastases were not reviewed in this study.

Data related to whether omental metastases could be detected at a higher ratio with total omentectomy could not be obtained from the literature. In this study, omental micrometastases was shown to be detected 5 times more often with total omentectomy $(11.3 \%$ vs $2.1 \%, p<0.001)$. Even if we could detect omental metastases with total omentectomy at a higher ratio, this may not demonstrate the real ratio of omental metastasis. The limitation in the pathologic examination is the reason. Detection of a metastasis of $1 \mathrm{~mm}$ in a $33 \times 24 \mathrm{~cm}$ omental specimen needs almost 800 sections in the pathologic examination, and this seems almost impossible in clinical practice (9). Therefore, total omentectomy will not solve the problem in the detection of metastasis in the omentum. In conclusion, one can say that the detection of omental micrometastases depends on chance. In endometrial cancer, the surgico-pathologic characteristics of the patients with omental metastasis have been evaluated in detail. Nevertheless, the reported data belonged to very small groups of patients (maximum n:6). In these studies, patients with omental metastases had high-risk pathologic characteristics at a higher ratio compared to patients of the normal endometrial cancer population, as expected. In the current study, high-risk factors were encountered at a high ratio. Almost half of the patients had nonendometrioid-type tumors, $62.5 \%$ of patients had grade 3 disease, $73 \%$ had myometrial invasion $\geq 1 / 2,66.7 \%$ had adnexal spread, $60.5 \%$ had metastases in the lymph nodes, and 48\% had cervical invasion (Table 1). While $43.8 \%$ of the patients had intra-abdominal spread other than the omentum, adnexa, and peritoneal cytology, there was no patient with extra-abdominal metastases.

We could not reach data in the literature with which we could compare the survival of patients with omental metastasis in endometrial cancer and data related to factors determining survival in these patients. Fujiwara et al. (10) reported that patients with omental metastasis died in 15 months, since Dilek et al. (8) reported that patients with microscopic metastasis died in 36 months and Metindir et al. (12) stated 3-y DFS to be $20 \%$ in this patient population. Nevertheless, the number of the cases reported in these studies was 4, 3, and 4, respectively. Therefore, it is not possible to get definite data related to the survival of patients with omental metastasis in endometrial cancer from these studies. In the current study, 1-y DFS and 2 -y DFS were $45.4 \%$ and $28.2 \%$, respectively; 1-y OS and 2-y OS were $71 \%$ and $40 \%$, respectively. Positive peritoneal cytology was a significant prognostic factor for both 2-yDFS and 2-y OS. Additionally, depth of myometrial invasion and grade and status of pelvic lymph nodes were determining factors for $2-y$ DFS, since presence of cervical invasion was predictive for $2-y$ OS. Peritoneal cytology is expected to be positive in patients with intra-abdominal spread, including omental metastases, whereas in this study, only $68.8 \%$ of patients had tumor cells in the peritoneal fluid. This situation may be explained by the spread of disease via regional lymphatics.

There was no difference between patients with microscopic and macroscopic omental metastasis in terms of survival; 2-y OS was similar for both groups of patients $(35.7 \%$ vs $36.8 \%$, respectively). However, 2-y DFS was $16 \%$ better in cases where there was only microscopic omental metastasis compared to the presence of intra-abdominal macroscopic metastasis (omental and other intra-abdominal metastases). This ratio for 2-y OS was $5 \%$ (Table 3 ). These differences were statistically insignificant $(\mathrm{p}=0.336, \mathrm{p}=0.775$, respectively).

In the presence of factors that were evaluated in the current study and that were found to be statistically insignificant, survival decreased significantly (Table 3). Especially, when the grade increased; when there was uterine serosal involvement, lymphovascular space invasion, adnexal spread, or para-aortic lymph node metastases; and when maximal debulking could not be achieved and radiotherapy was used as the adjuvant treatment, survival decreased. These differences were not statistically significant, since the study group was small and the factors were distributed disproportionately. Although total omentectomy was important for detecting omental micrometastases according to this study, the type of omentectomy was not associated with survival in patients with omental metastasis. However, 2 -y OS was $10 \%$ better in patients who had a total omentectomy (Table 3).

Survival in the present study may be compared only with the results of studies analyzing patients with stage IVB endometrial cancer. Although stage IVB endometrial cancer includes a heterogeneous group of patients, age, extra-abdominal spread, lymph node metastases, adjuvant therapy, grade, cervical invasion, depth of myometrial invasion, performance status of the patients, and especially aggressive surgery were all reported to determine survival (20-22). In these studies and in a meta-analysis evaluating cytoreductive surgery in patients with primary and recurrent endometrial cancer, extent of surgery was shown to be the main factor determining survival in patients with stage IVB endometrial cancer (20-23). In a study by Bristow et al. (21), patients who had optimal debulking surgery were found to survive 3 times longer than patients for whom optimal debulking could not be achieved. The subgroup analysis of the same study showed that in the optimally debulked group, patients with only microscopic residual disease survived longer than patients with gross disease smaller than $1 \mathrm{~cm}$. Ayhan et al. (22) presented 2 -y OS as 30\% for patients with stage IVB endometrial cancer for whom $32 \%$ maximal debulking and 60\% optimal debulking were achieved. In the current study, in which $83.3 \%$ maximal debulking was achieved, 2 -y OS was $40 \%$. In the patients for whom maximal debulking was achieved, 20\% improvement in 2-y DFS was seen. However, the improvement in 2-y OS was only $4 \%$. Additionally, the patients for whom maximal or optimal cytoreduction could not be achieved died within 2 years. 
We thought that it was inappropriate to compare the results of this study and studies analyzing patients with stage IVB disease in terms of survival -that is to say, in the current study, there was a $10 \%$ difference in 2-y OS in comparison to the study by Ayhan et al. (22). This difference may be explained by the difference in the ratios of maximal debulking, as well as by the inequality between the patient groups. In the study of Ayhan et al. (22), there were extra-abdominal metastases in 16\%; liver, spleen, or diaphragmatic spread in 24\%; small intestine involvement in 24\%; and large intestine involvement in $19 \%$ of the patients. Omental metastasis was detected in only half of the patients. As can be seen, tumors were more prevalent in the patient population in the analysis of Ayhan et al. (22) compared to the current study, which evaluated only patients with omental metastasis. It is also inappropriate to compare these results with the Japanese multi-center study evaluating stage IVB endometrial cancer. In the study by Eto et al. (20), 248 patients were analyzed, and only $58 \%$ of these patients had omental metastasis, since $38 \%$ had extra-abdominal spread. Eventually, the patient population of the current study was limited compared to the patients in the studies analyzing cases with stage IVB endometrial cancer. Consequently, there are no data in the literature that we can directly compare the results of this study with in terms of survival.

There is no standard treatment for stage IVB endometrial cancer with regard to adjuvant therapy. Nevertheless, there is a consensus on the necessity of systemic treatment, since disease in this stage should be accepted as systemic. Eto et al. reported that chemotherapy with or without radiotherapy was a determining prognostic factor for survival (20). Similar results were stated in the study of Ayhan et al. (22). In the Gynecologic Oncology Group study, in which Randall et al. (24) compared whole abdominal radiotherapy with adriamycin and cisplatin combination, survival was shown to improve with chemotherapy in advanced-stage endometrial cancer. It was reported that extra-abdominal recurrence decreased from $19 \%$ to $10 \%$ with chemotherapy, since local recurrence increased from $13 \%$ to $18 \%$. In the current study, it was shown that distant recurrence decreased with chemotherapy, while central recurrences increased. Recurrence in the pelvis was observed in $20 \%$ of the patients who took only radiotherapy, since this ratio was $33 \%$ for patients who took chemotherapy. On the other hand, $48 \%$ of the patients who took chemotherapy and $60 \%$ of the patients who took radiotherapy had extra-abdominal metastases. Additionally, compared to radiotherapy, chemotherapy improved 2-y DFS and 2-y OS by $16 \%$ and 30\%, respectively (Table 3). Nevertheless, these differences were not statistically significant $(\mathrm{p}=0.492, \mathrm{p}=0.223$, respectively).

In conclusion, omental metastasis in endometrial cancer is most probably more common than reported. We thought that the omentum should be evaluated surgically in endometrial carcinoma. However, although total omentectomy has a role in the detection of omental micrometastases, its effect on survival in the patients with omental metastasis is not clear. The effect of total omentectomy on survival in patients with endometrial carcinoma and especially in patients without high-risk factors is not known, but it is obvious that it may make a difference.
It may help to define the stage and to manage the patient, and additionally, it may provide tumoral debulking of possibly undiagnosed metastases, even if the metastases could not be detected with total omentectomy. Nonetheless, it is not realistic to suggest total omentectomy or to refuse this procedure in patients with endometrial cancer according to the results of this study, evaluating only patients with omental metastasis. In this patient population, aggressive surgery improved survival, although it was not statistically significant. The patients with suboptimal debulking surgery died of disease in 2 years. In these patients, maximal debulking should be the goal of the surgery. Similarly, even though the effect of systemic treatment was statistically insignificant, survival greatly improved with the administration of chemotherapy. The current study is a retrospective study, and although it is the largest series of patients with omental metastasis in endometrial cancer that has been analyzed in detail in the literature, it was too small a series to make definite conclusions in terms of survival. Nevertheless, omental metastasis is a poor prognostic factor in endometrial carcinoma, and two-thirds of these patients died at the end of the second year. Therefore, this patient group is a group in which new treatment modalities should be developed. Patients with omental metastases from endometrial cancer should preferably be treated in multi-center studies.

Ethics Committee Approval: Ethics committee approval was received for this study from the local committee of the institution.

Informed Consent: $N / A$.

Peer-review: Externally peer-reviewed.

Author contributions: Concept - T.T.; Design - A.K., T.T.; Supervision - G.T.; Resource - F.K.; Materials - L.K.; Data Collection\&/or Processing - H.I., L.K.; Analysis\&/or Interpretation - I.Ü.; Literature Search - A.K., T.T.; Writing - T.T., I.Ü.; Critical Reviews - F.K., G.T.

Conflict of Interest: No conflict of interest was declared by the authors.

Financial Disclosure: The authors declared that this study has received no financial support.

\section{References}

1. Amant F, Moerman P, Neven P, Timmerman D, Van Limbergen E, Vergote I. Endometrial cancer. Lancet 2005; 366: 491-505. [CrossRef]

2. Creasman WT, Odicino F, Maisonneuve P, et al. Carcinoma of the corpus uteri. FIGO 26th Annual Report on the Results of Treatment in Gynecological Cancer. Int J Gynaecol Obstet 2006; 95 (Suppl 1): S105-43. [CrossRef]

3. Cook AM, Lodge N, Blake P. Stage IV endometrial carcinoma: a 10 year review of patients. Br J Radiol 1999; 72: 485-8. [CrossRef]

4. ASTEC study group, Kitchener H, Swart AM, Qian Q, Amos C, Parmar MK. Efficacy of systematic pelvic lymphadenectomy in endometrial cancer (MRC ASTEC trial): A randomized study. Lancet 2009; 373: 125-36. [CrossRef]

5. Chan JK, Wu H, Cheung MK, Shin JY, Osann K, Kapp DS. The outcomes of 27,063 women with unstaged endometrioid uterine cancer. Gynecol Oncol 2007; 106: 282-8. [CrossRef] 
6. Larson DM, Johnson K, Olson KA. Pelvic and para-aortic lymphadenectomy for surgical staging of endometrial cancer: Morbidity and mortality. Obstet Gynecol 1992; 79: 998-1001.

7. Hidaka T, Kato K, Yonezawa R, Shima T, Nakashima A, Nagira K, et al. Omission of lymphadenectomy is possible for low-risk corpus cancer. Eur J Surg Oncol 2007; 33: 86-90. [CrossRef]

8. Dilek S, Dilek U, Dede M, Deveci MS, Yenen MC. The role of omentectomy and appendectomy during the surgical staging of clinical stage I endometrial cancer. Int J Gynecol Cancer 2006; 16: 795-8. [CrossRef]

9. Usubütün A, Ozseker HS, Himmetoglu C, Balci S, Ayhan A. Omentectomy for gynecologic cancer: How much sampling is adequate for microscopic examination? Arch Pathol Lab Med 2007; 131: 1578-81.

10. Fujiwara H, Saga Y, Takahashi K, Ohwada M, Enomoto A, Konno R, et al. Omental metastases in clinical stage I endometrioid adenocarcinoma. Int J Gynecol Cancer 2008; 18: 165-7. [CrossRef]

11. Freij MA, Burbos N, Mukhopadhyay D, Lonsdale R, Crocker S, Nietto JJ. The role of omental biopsy in endometrial cancer staging. Gynecol Surg 2009; 6: 215-53. [CrossRef]

12. Metindir J, Dilek GB. The role of omentectomy during the surgical staging in patients with clinical stage I endometrioid adenocarcinoma. J Cancer Res Clin Oncol 2008; 134: 1067-70. [CrossRef]

13. Saygili U, Kavaz S, Altunyurt S, Uslu T, Koyuncuoglu M, Erten O. Omentectomy, peritoneal biopsy and appendectomy in patients with clinical stage I endometrial carcinoma. Int J Gynecol Cancer 2001; 11: 471-4. [CrossRef]

14. Nieto JJ, Gornall R, Toms E, Clarkson S, Hogston P, Woolas RP. Influence of omental biopsy on adjuvant treatment field in clinical Stage I endometrial carcinoma. BJOG 2002; 109: 576-8. [CrossRef]

15. Chen SS, Spiegel G. Stage I endometrial carcinoma. Role of omental biopsy and omentectomy. J Reprod Med 1991; 36: 627-9.
16. WHO handbook for reporting results of cancer treatment. WHO Offset Publication 1979; No: 148.

17. Creasman WT, Morrow CP, Bundy BN, Homesley HD, Graham JE, Heller PB. Surgical pathologic spread patterns of endometrial cancer. A Gynecologic Oncology Group Study. Cancer 1987; 60 (8 Suppl): 2035-41. [CrossRef]

18. Klopp AH, Zhang Y, Solley T, Amaya-Manzanares F, Marini F, Andreeff $\mathrm{M}$, et al. Omental adipose tissue-derived stromal cells promote vascularization and growth of endometrial tumors. Clin Cancer Res 2012; 18: 771-82. [CrossRef]

19. Duzguner S, Ilgin Hilal, Tasci Tolga, Duzguner I, Turan T, Boran N, et al. Analysis of mixed type endometrial carcinoma. J Turk Soc Obstet Gynecol 2014; 2: 119-25.

20. Eto T, Saito T, Kasamatsu T, Nakanishi T, Yokota H, Satoh T, et al. Clinicopathological prognostic factors and the role of cytoreduction in surgical stage IVb endometrial cancer: A retrospective multi-institutional analysis of 248 patients in Japan. Gynecol Oncol 2012; 127: 338-44. [CrossRef]

21. Bristow RE, Zerbe MJ, Rosenshein NB, Grumbine FC, Montz FJ. Stage IVB endometrial carcinoma: the role of cytoreductive surgery and determinants of survival. Gynecol Oncol 2000; 78: 85-91. [CrossRef]

22. Ayhan A, Taskiran C, Celik C, Yuce K, Kucukali T. The influence of cytoreductive surgery on survival and morbidity in stage IVB endometrial cancer. Int J Gynecol Cancer 2002; 12: 448-53. [CrossRef]

23. Barlin JN, Puri I, Bristow RE. Cytoreductive surgery for advanced or recurrent endometrial cancer: a meta-analysis. Gynecol Oncol 2010; 118: 14-8. [CrossRef]

24. Randall ME, Filiaci VL, Muss H, Spirtos NM, Mannel RS, Fowler L, et al. Randomized phase III trial of whole-abdominal irradiation versus doxorubicin and cisplatin chemotherapy in advanced endometrial carcinoma: A Gynecologic Oncology Group study. J Clin Oncol 2006; 24: 36-44. [CrossRef] 